\title{
Differential responses of post-exercise recovery leg blood flow and oxygen uptake kinetics in HFPEF versus HFREF
}

\author{
Richard B Thompson ${ }^{1 *}$, Joseph J Pagano ${ }^{1}$, Ian Paterson ${ }^{3}$, Jason Dyck ${ }^{4}$, Dalane Kitzman ${ }^{5}$, Mark Haykowsky ${ }^{2}$ \\ From 19th Annual SCMR Scientific Sessions \\ Los Angeles, CA, USA. 27-30 January 2016
}

\section{Background}

Delayed oxygen uptake $\left(\mathrm{VO}_{2}\right)$ kinetics during recovery from a bout of endurance exercise have been shown to be an important prognostic marker of all-cause mortality in chronic heart failure (HF), where skeletal muscle is the predominant $\mathrm{O}_{2}$ consumer. Few studies have examined skeletal muscle $\mathrm{O}_{2}$ delivery/utilization, and no previous study has evaluated the differences between HF patients with reduced LVEF (HFREF) versus those with preserved LVEF (HFPEF). We used novel MRI-based techniques to non-invasively measure quadriceps (leg) blood flow, $\mathrm{O}_{2}$ extraction and $\mathrm{VO}_{2}$ recovery kinetics in clinically stable patients diagnosed with HFREF or HFPEF.

\section{Methods \\ Leg flow and venous $\mathrm{O}_{2}$ saturation $\left(\% \mathrm{SaO}_{2}\right)$ were mea- sured in the femoral vein post-exercise (knee-extension) using MRI (Fig. 1A, B) as previously described (Magn Reson Med. 2014 Dec 22. doi: 10.1002/mrm.25564). These values in conjunction with arterial oxygen saturation (\% $\mathrm{SaO}_{2}$, pulse oximeter), hemoglobin (Hgb) and hematocrit (from blood sampled prior to exercise) are used to calcu- late leg $\mathrm{VO}_{2}$, from the Fick equation (Fig. 1B). All subjects performed $4 \mathrm{~min}$. of single-leg knee-extension exercise at $85 \%$ of their pre-determined peak power output. Leg blood flow, oxygen extraction and $\mathrm{VO}_{2}$ were measured continuously during recovery for 3 minutes, starting within 1 second of exercise cessation. Recovery kinetics were quantified as the mean response time (MRT - defined in Fig. 1E, lower right panel) for all parameters,}

'Biomedical Engineering, University of Alberta, Edmonton, $A B$, Canada Full list of author information is available at the end of the article with comparison to healthy younger male controls (HC) from a previous study using the same methodology.

\section{Results}

$\operatorname{HFPEF}(\mathrm{n}=5, \operatorname{LVEF}=36 \pm 11 \%, 69 \pm 9 \mathrm{yrs})$ and HFPEF $(n=5, \operatorname{LVEF}=57 \pm 6 \%, 67 \pm 11$ yrs) patients were recruited from the Alberta HEART study. Quadriceps muscle mass, peak leg flow, $\mathrm{A}-\mathrm{VO}_{2}$ difference and $\mathrm{VO}_{2}$ were not significantly different between HFPEF and HFREF ( $p>0.05$ for all). However, HFREF patients had severe impairment of $\mathrm{VO}_{2}$ recovery kinetics (increased $M R T$ ), while HFPEF had a moderate impairment, as compared to $\mathrm{HC}$ ( $\mathrm{p}<0.05$ for all comparison, Fig. 1E, bottom right). This is understood by considering the underlying flow and oxygen extraction kinetics. From Fig. 1D) both HF groups showed similarly impaired A- $\mathrm{VO}_{2}$ recovery kinetics compared to controls ( $\mathrm{p}<$ 0.05), however, the HFREF group had marked impairment in leg blood flow recovery dynamics, compared to both HFPEF and control groups ( $\mathrm{p}<0.05$ for both comparisons, Fig. 1C). Thus, it is the impaired recovery of flow in HFREF group which distinguishes the HFREF and HFPEF groups.

\section{Conclusions}

Whole body $\mathrm{VO}_{2}$ recovery kinetics are related to the degree of functional impairment and are strongly predictive of mortality. We show for the first time that muscle-specific $\mathrm{VO}_{2}$ recovery kinetics are significantly more delayed in HFREF compared to HFPEF (reflecting a larger oxygen debt for a similar amount of work). These findings suggest distinct mechanisms may underlie the reduced exercise capacity in HFREF vs HFPEF, with potentially distinct diagnostic metrics and therapeutic approaches. 
A)

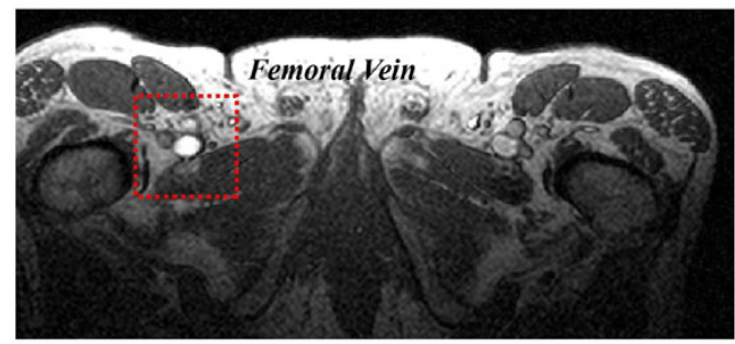

B)

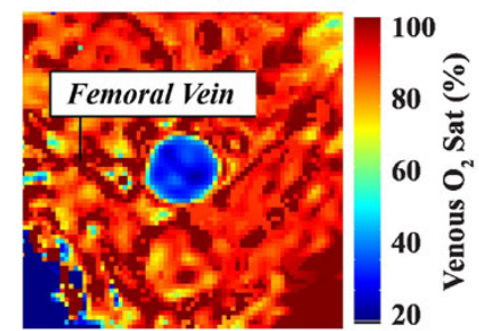

60 Seconds Post Exercise

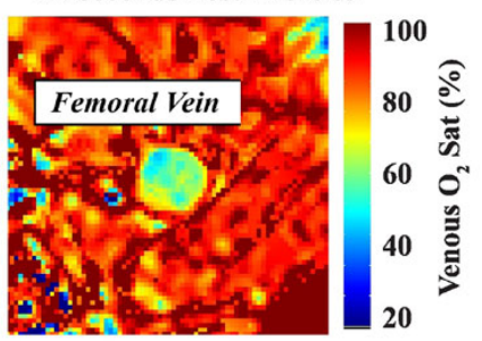

$\mathrm{VO}_{2}=$ Flow $* \mathrm{~A}-\mathrm{V} \mathrm{O}_{2}$ difference

$\mathrm{VO}_{2} \sim$ Flow $*\left(\mathrm{Hgb}^{*} 1.34 *\left[\% \mathrm{O}_{2}\right.\right.$ Sat. $_{\text {Ar. }}-{ } \% \mathrm{O}_{2}$ Sat. $\left.\left._{\text {Venous }}\right]\right)$
C)

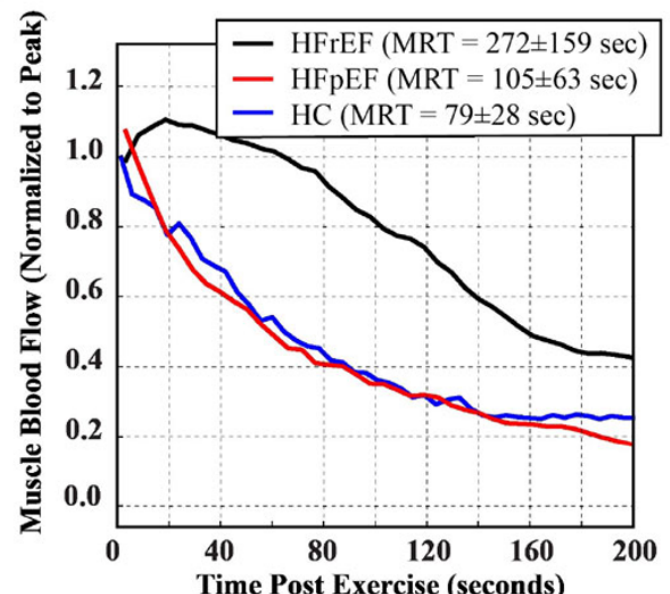

D)

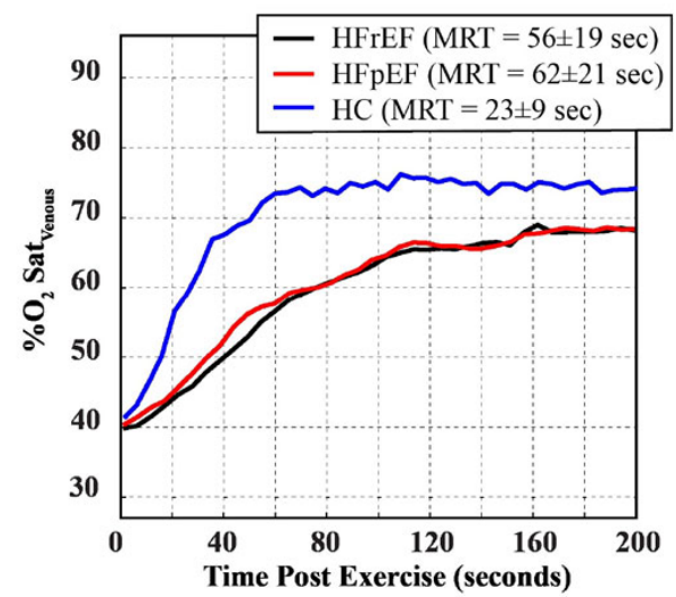

E)

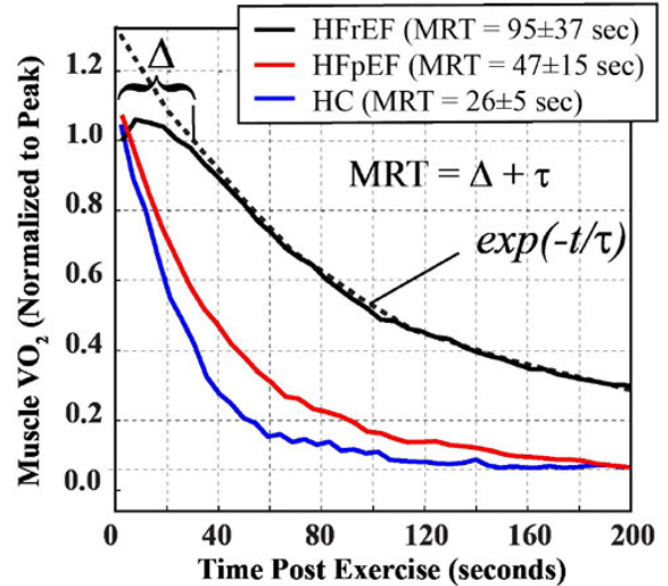

Figure 1 A) Anatomic image from a patient showing femoral vein location used for evaluation of flow and venous $\mathrm{O} 2$ saturation. B) $\mathrm{O} 2$ saturation images from a patient at two time points $(2 \mathrm{sec}$. and $60 \mathrm{sec}$.) following exercise, and the Fick equation for calculation of VO2. C) to E) show the average recovery curves for flow, venous $\mathrm{O} 2$ saturation and calculated leg VO2, for HFPEF (black), HFPEF (red) and healthy controls $(H C$, blue). MRT = mean response time, which is the sum of the delay term $(\Delta)$, to the onset of exponential recovery, and time constant of the best-fit mono-exponential decay function ( $t$ ), as shown in E). HFPEF = heart failure with preserved ejection fraction, HFREF = heart failure with reduced ejection fraction, $\mathrm{Hgb}=$ hemoglobin concentration. 


\section{Authors' details}

'Biomedical Engineering, University of Alberta, Edmonton, AB, Canada.

${ }^{2}$ College of Nursing and Health Innovation, University of Texas at Arlington, Arlington, TX, USA. ${ }^{3}$ Medicine, University of Alberta, Edmonton, AB, Canada. ${ }^{4}$ Pediatrics, University of Alberta, Edmonton, $\mathrm{AB}$, Canada. ${ }^{5}$ Cardiology and

Geriatrics, Wake Forest University, Wake Forest, NC, USA.

Published: 27 January 2016

doi:10.1186/1532-429X-18-S1-09

Cite this article as: Thompson et al: Differential responses of postexercise recovery leg blood flow and oxygen uptake kinetics in HFPEF versus HFREF. Journal of Cardiovascular Magnetic Resonance 2016 18(Suppl 1):09.

Submit your next manuscript to BioMed Central and take full advantage of:

- Convenient online submission

- Thorough peer review

- No space constraints or color figure charges

- Immediate publication on acceptance

- Inclusion in PubMed, CAS, Scopus and Google Scholar

- Research which is freely available for redistribution

Submit your manuscript at www.biomedcentral.com/submit 